\title{
Energy, economic, and environmental analysis of a flat-plate solar collector operated with $\mathrm{SiO}_{2}$ nanofluid
}

\author{
M. Faizal $\cdot$ R. Saidur $\cdot$ S. Mekhilef $\cdot$ \\ A. Hepbasli • I. M. Mahbubul
}

Received: 31 March 2014/Accepted: 21 October 2014/Published online: 5 November 2014

(C) Springer-Verlag Berlin Heidelberg 2014

\begin{abstract}
To overcome the environmental impact and declining source of fossil fuels, renewable energy sources need to meet the increasing demand of energy. Solar thermal energy is clean and infinite, suitable to be a good replacement for fossil fuel. However, the current solar technology is still expensive and low in efficiency. One of the effective ways of increasing the efficiency of solar collector is to utilize high thermal conductivity fluid known as nanofluid. This research analyzes the impact on the performance, fluid flow, heat transfer, economic, and environment of a flat-plate solar thermal collector by using silicon dioxide nanofluid as absorbing medium. The analysis is based on different volume flow rates and varying nanoparticles volume fractions. The study has indicated that nanofluids containing small amount of nanoparticles have higher heat transfer coefficient and also higher energy and exergy efficiency than base fluids. The measured viscosity of nanofluids is higher than water but it gives
\end{abstract}

M. Faizal

Department of Engineering, School of Liberal Arts and Sciences, Taylor's University Lakeside Campus, 47500 Selangor, Malaysia

M. Faizal · R. Saidur $(\bowtie)$ - I. M. Mahbubul Department of Mechanical Engineering, Faculty of Engineering, University of Malaya, 50603 Kuala Lumpur, Malaysia e-mail: saidur@um.edu.my; saidur912@yahoo.com

S. Mekhilef

Power Electronics and Renewable Energy Research Laboratory (PEARL), Department of Electrical Engineering, Faculty of Engineering, University of Malaya, 50603 Kuala Lumpur, Malaysia

A. Hepbasli

Department of Energy Systems Engineering, Faculty of

Engineering, Yasar University, 35100 Izmir, Turkey negligible effect on pressure drop and pumping power. Using $\mathrm{SiO}_{2}$ nanofluid in solar collector could also save $280 \mathrm{MJ}$ more embodied energy, offsetting $170 \mathrm{~kg}$ less $\mathrm{CO}_{2}$ emissions and having a faster payback period of 0.12 years compared to conventional water-based solar collectors.

Keywords $\mathrm{SiO}_{2}$ nanofluid - Flat-plate solar collector . Heat transfer $\cdot$ Economic $\cdot$ Exergy

Introduction

Renewable energies are very important in the world economy today because they are sustainable, safe, and clean. World energy demand is increasing and expected to accelerate more in the future, while the fossil oil sources and production are declining. Climate change and environmental pollution are becoming huge global problems. Solar energy is an unlimited and free source of energy that can meet the world's future energy needs without harming the earth. Therefore, many studies have been conducted to address this issue. Tora and El-Halwagi (2009) had developed an optimal design of energy system to integrate solar systems and fossil fuel for sustainable and stable power outlet. Nemet et al. (2012) continued the work further by developing captured solar energy curve and minimal capture temperature curve to maximize the solar thermal energy delivered to the process. Ranjan and Kaushik (2013) performed an energy and exergy analysis of active solar distillation system integrated with solar pond that can contribute to water security and sustainability. Sanchez-Bautista et al. (2014) presented an optimization model for the optimal design of water-heating system for homes in Mexico. In that model, location, solar radiation, inhabitants, and time-based consumption pattern 
were accounted to determine the optimal design of integrated solar, and boilers water-heating systems aimed to minimized cost and greenhouse gas emissions. There is a good potential for solar thermal energy in Malaysia due to its location on the equatorial, with hot and humid climate throughout the year and monthly solar radiation approximately around $400-600 \mathrm{MJ} / \mathrm{m}^{2}$ (Mekhilef et al. 2012). However, the major problem for current solar heater is that the efficiency is low, and the price is ten times more expensive than electric heater. One of the effective methods to increase the efficiency of solar collector is to replace the working fluid with nanofluids.

Nanofluids were first introduced by Choi (1995), which are nanoparticles additives in liquid solvents. Researches on enhanced thermal efficiency of solar collector by applying nanofluids have been made in the past few years by the researchers. An experimental investigation conducted by Yousefi et al. (2012c) on the effect of $\mathrm{Al}_{2} \mathrm{O}_{3}$ based nanofluid shown an efficiency increase of $28.3 \%$ of flat-plate solar collectors. Lenert and Wang (2012) presented a model and performed an experimental study of concentrated solar power application using carbon-coated cobalt (C-Co) nanoparticles and Therminol VP-1-based fluid. They concluded that the efficiency was more than $35 \%$ with nanofluid, and the efficiency would increase with the increasing of nanofluid height. Lu et al. (2011) showed that the application of copper oxide $(\mathrm{CuO})$ nanoparticles in evacuated tube solar collectors has significantly enhanced the thermal performance of evaporator which resulted in $30 \%$ evaporating heat transfer coefficient increase compared to water as working fluid. $5 \%$ improvement in the efficiency was found out by Otanicar et al. (2010) using variety of nanoparticles with water as base fluid for micro-solar-thermal collector. Shin and Banerjee (2011) applied novel nanomaterials in molten salts base fluid to concentrated solar power coupled with thermal storage and experienced an enhancement in operational efficiencies. Taylor et al. (2011) used graphitebased nanofluids in high flux solar collectors that resulted in $10 \%$ increase in the efficiency. Zamzamian et al. (2014) performed an experimental study to investigate the effect of copper $(\mathrm{Cu})$ nanoparticle on the efficiency of a flat-plate solar collector in different volume flow rates and weight fractions of the nanoparticles. It was found that the optimum point for solar collector efficiency has been reached up to $0.3 \mathrm{wt} \% \mathrm{Cu}$ nanofluid at $1.5 \mathrm{~L} / \mathrm{min}$.

Smaller and more compact design of solar collector has become possible because of higher thermal conductivity of nanofluids. Because of higher thermal conductivity and efficiency of nanofluids, smaller and compact design of solar thermal collectors has become possible without affecting the output desired. Smaller size collector can reduce the material usage, cost, and energy required in
Table 1 Properties of different nanomaterials and base fluids (Kamyar et al. 2012; Namburu et al. 2007)

\begin{tabular}{llll}
\hline Materials & $\begin{array}{l}\text { Specific heat, } \\
C_{\mathrm{p}}(\mathrm{J} / \mathrm{kg} \mathrm{K})\end{array}$ & $\begin{array}{l}\text { Thermal } \\
\text { conductivity, } \\
k(\mathrm{~W} / \mathrm{m} \mathrm{K})\end{array}$ & $\begin{array}{l}\text { Density, } \\
\rho\left(\mathrm{kg} / \mathrm{m}^{3}\right)\end{array}$ \\
\hline $\begin{array}{c}\text { Alumina } \\
\left(\mathrm{Al}_{2} \mathrm{O}_{3}\right)\end{array}$ & 773 & 40 & 3,960 \\
$\begin{array}{c}\text { Copper oxide } \\
(\mathrm{CuO})\end{array}$ & 551 & 33 & 6,000 \\
$\begin{array}{c}\text { Titanium } \\
\text { oxide }\left(\mathrm{TiO}_{2}\right)\end{array}$ & 692 & 8.4 & 4,230 \\
$\begin{array}{c}\text { Silicon } \\
\text { dioxide }\left(\mathrm{SiO}_{2}\right)\end{array}$ & 765 & 36 & 2,330 \\
$\begin{array}{c}\text { Water }\left(\mathrm{H}_{2} \mathrm{O}\right), \\
\text { base fluid }\end{array}$ & 4,182 & 0.60 & 1,000 \\
\hline
\end{tabular}

manufacturing (Leong et al. 2012). Some studies were made on the potential of size reduction of various engineering applications using nanofluids. These were based on vehicle's weight reduction (Saidur and Lai 2011), building heat exchanger's heat transfer area (Kulkarni et al. 2009), reduction of air frontal area of a car radiator (Leong et al 2010), and the size reduction of shell and tube recovery exchanger (Leong et al. 2012). Other studies had also been made to evaluate the economic and environmental impact of solar hot water system (Kalogirou 2004, 2008; Tsillingiridis et al. 2004; Ardente et al. 2005). One particular study focused on the environmental and economic analysis of direct absorption micro-solar thermal collector utilizing graphite nanofluid (Otanicar 2009). Studies on the potential of size reduction of flat-plate solar collectors has also been reported for multi-walled carbon nanotubes nanofluid (Faizal et al. 2013b) and $\mathrm{Al}_{2} \mathrm{O}_{3}$ nanofluid (Faizal et al. 2014).

In thermodynamics analysis, the energy equation alone is insufficient to evaluate the flat-plate solar collector efficiency. The second law or exergy analysis is more effective to determine the source and magnitude of irreversibility, and can be used to improve the efficiency of the system. Exergy is the maximum output that can be achieved relative to the environment temperature (Cengel and Boles 2010). Studies on exergy analysis have been conducted by Saidur et al. (2012) on various solar energy applications and (Farahat et al. 2009) flat-plate solar collectors. Mahian et al. (2013) also comprehensively reviewed the entropy generation in nanofluids flow, while Alim et al. (2013) made an analytical analysis of entropy generation in a flat-plate solar collector using different types of metal oxide nanofluids. However, to the best of the authors' knowledge, experimental studies on solar collectors performance analysis using $\mathrm{SiO}_{2}$ nanofluid have not yet appeared in the open literature even though a lot of 
simulation works have been done, and all the studies on the exergy analysis on flat-plate solar thermal collectors are either simulation or theoretical. Therefore, this study focuses on the thermodynamics performance, heat transfer characteristic, economic, and environmental assessment of flat-plate solar collectors applying $\mathrm{SiO}_{2}$ nanofluid to fill up those gaps.

\section{Properties of nanofluids}

By considering the application of nanofluids as the base of the research, various researchers have published research outcomes on the properties of nanoparticles and thermal properties of nanofluids. Table 1 shows the published specific heat, thermal conductivity, and density of different nanoparticles.

However, all these special characteristics cannot be achieved unless the nanoparticles are properly dispersed and stable.

\section{Preparation and characterization of nanofluid}

Stability of nanofluids for long term is the major issue for the engineering applications (Liu and Liao 2008). Nanoparticles in the base fluid naturally will aggregate and sediment. In theory, there is existence of both attractive and repulsive forces between particles (Ise and Sogami 2005). The attractive force is the van der Waals force, and the repulsive force is the electrostatic repulsion when particles get too close together. If the repulsive force is stronger than the attractive force, nanoparticles in the base fluid can remain stable or otherwise it will aggregate and serious aggregation will lead to sedimentation. Adding surfactants to the nanofluid can enhance the electrostatic repulsion of nanoparticles. Surfactants such as sodium dodecyl benzene sulfonate, sodium dodecyl sulfate, or Triton X-100 had been tested and proven to stabilize nanofluid (Wang 2009). However, the effect might be affected when the Brownian motion of nanoparticles is too strong or when the nanofluid is heated. Another way to stabilize nanofluid is by changing the $\mathrm{pH}$ value of the solution (Yousefi et al. 2012a). The $\mathrm{pH}$ of isoelectric point for nanoparticles carries no electrical charge and, therefore, causes no interparticle repulsion force which in turn causing more aggregated solution. The more differences between the $\mathrm{pH}$ of nanofluid and $\mathrm{pH}$ of isoelectric point may cause less aggregation and better dispersion. The $\mathrm{pH}$ of $\mathrm{SiO}_{2}$ in this study had been measured to be 6.5 using Hanna Instruments microprocessor $\mathrm{pH}$ meter, while the $\mathrm{pH}$ of isoelectric point for $\mathrm{SiO}_{2}$ is around 3 (Kosmulski 2001). A better way to stabilize nanofluid was proposed by Yang and Liu (2010) who is to graft polymers

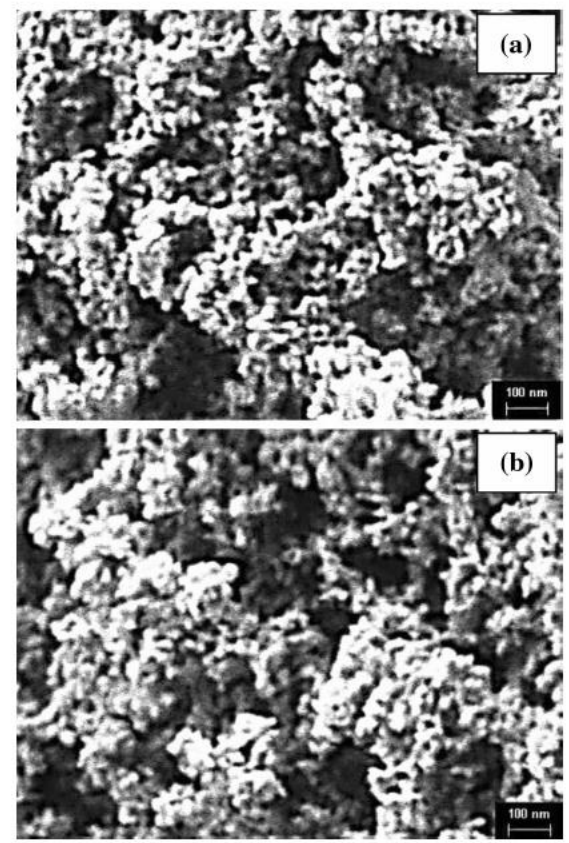

Fig. 1 SEM images of $\mathrm{SiO}_{2}$ nanoparticle a before and $\mathbf{b}$ after the experiment

on to the surface of nanoparticles and also known as surface functionalization. Silanes were grafted on silica nanoparticles making "Si-O-Si" covalent bonding and resulting in steric stabilization effect even when heated. Functionalized $\mathrm{SiO}_{2}$ nanoparticles have been reported to keep dispersing well after 12 months, and no sedimentation was observed (Chen et al. 2013).

The $\mathrm{SiO}_{2}$ nanoparticles used in the experiments were obtained from US Research Nanomaterials, Inc. with $15 \mathrm{~nm}$ in outer diameter, coated with $2 \mathrm{wt} \%$ silane, which have a density of $2.4 \mathrm{~g} / \mathrm{cm}^{3}$ and a $\mathrm{pH}$ value of 6-6.5. For this study, $3 \mathrm{~L}$ of 0.2 and $0.4 \%$ volume fraction of $\mathrm{SiO}_{2}$ nanofluid were prepared. The amount of nanoparticles needed for the intended volume fraction of the solution was calculated first from

$\phi_{\mathrm{n}}=\frac{m_{\mathrm{n}} / \rho_{\mathrm{n}}}{m_{\mathrm{n}} / \rho_{\mathrm{n}}+m_{\mathrm{w}} / \rho_{\mathrm{w}}}$,

where $\phi_{\mathrm{n}}$ is the volume fraction of nanoparticles in nanofluid $(\%), m_{\mathrm{n}}$ is the mass of nanoparticle $(\mathrm{kg}), m_{\mathrm{w}}$ is the mass of water $(\mathrm{kg}), \rho_{\mathrm{n}}$ is the density of nanoparticle $\left(\mathrm{kg} / \mathrm{m}^{3}\right)$, and $\rho_{\mathrm{w}}$ is the density of water $\left(\mathrm{kg} / \mathrm{m}^{3}\right)$.

The nanofluids were prepared using two-step method. It was prepared by dispersing nanoparticles into distilled 


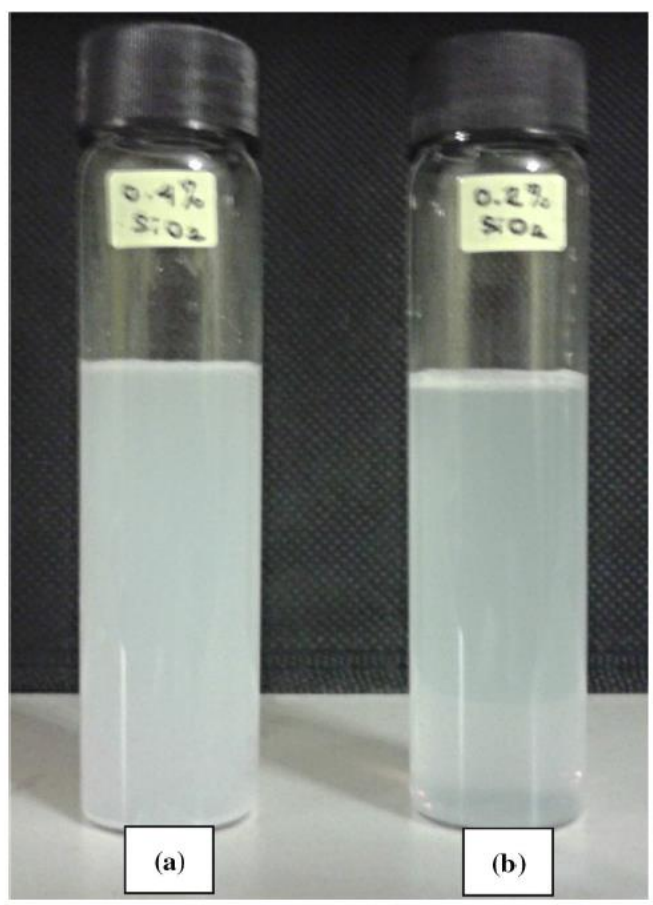

Fig. 2 Pictures of a $0.4 \%$ and b $0.2 \%$ nanofluid after 6 months

water using ultrasonicator and high pressure homogenizer (up to 2,000 bar capacity) to obtain a homogenously dispersed solution. The microstructure and composition of the nanoparticles are characterized using field emission scanning electron microscopy (FESEM; Model AURIGA, Zeiss, Germany). Nanoparticles are characterized before and after experiment with FESEM at $1 \mathrm{kV}$ accelerating voltage. 50,000 times magnification is used to capture the images at the $100 \mathrm{~nm}$ scale. Figure 1 shows the FESEM images of $\mathrm{SiO}_{2}$ nanoparticles mixed in distilled water. The picture of the prepared nanofluid is shown in Fig. 2. As it is shown, the prepared nanofluid can still keep dispersing well after 6 months, and no sedimentation was observed.

The viscosity of prepared nanofluid was measured using LVD-III ultra-programmable rheometer (Brookfield, USA) with $\pm 0.5 \%$ uncertainty. The viscosity of all samples was measured at the constant shear rate of $73.38 \mathrm{~s}^{-1}$, while the ULA spindle rotating was $60 \mathrm{rpm}$. For the temperature variation, the refrigerated circulator bath (Model AD07R$40-12 \mathrm{E}$, Polyscience, USA) with accuracy $\pm 0.1{ }^{\circ} \mathrm{C}$ was connected to the water jacket of ULA that was attached to the rheometer. The temperature of each sample was varied from 25 to $85{ }^{\circ} \mathrm{C}$ with $20{ }^{\circ} \mathrm{C}$ intervals to investigate the

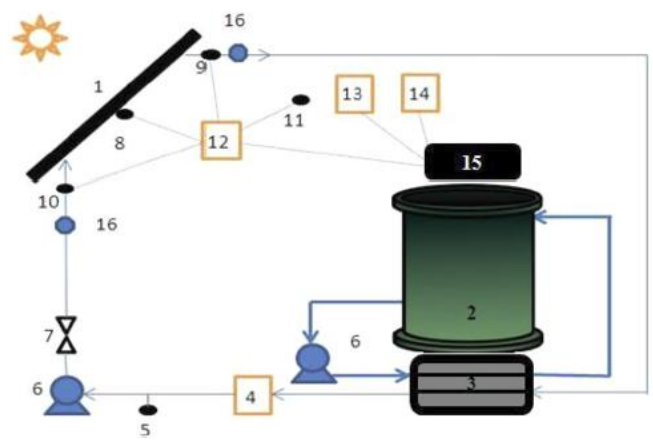

Fig. 3 A schematic diagram of the experiment: 1 flat-plate solar collector, 2 water tank, 3 heat exchanger, 4 flow meter, 5 drain, 6 pump, 7 valve, 8 thermocouple (plate temperature), 9 thermocouple (working fluid out), 10 thermocouple (working fluid in), 11 thermocouple (ambient), 12 thermometer, 13 TES 1333R solar meter, 14 PROVA (AV M-07) anemometer, 15 data logger, 16 pressure transducer

effect of temperature on the viscosity of nanofluid. Each experiment was repeated three times to get the more precise values. The mean value of the three data was considered for the analysis.

\section{Experimental procedure}

A schematic diagram of the experiment is shown in Fig. 3. The solar collector experimental setup indicated in Fig. 4 was constructed at the University of Malaya, Kuala Lumpur, Malaysia. The specifications of the flat-plate solar collector used in this study are given in Table 2 . The tilt angle of this solar collector is $22^{\circ}$. Two electrical pumps were used in this system to pump the working fluid and water from the tank. The water from the tank is used to absorb the heat from the system cycle. A plate heat exchanger is used to transfer the heat from the working fluid of the solar thermal system cycle to the water inside the tank. The experiments were conducted using different volume flow rates from 1 to $3 \mathrm{~L} / \mathrm{s}$ for each type of the working fluids. A flow meter with a controlling valve was connected to control the mass flow rate of the working fluid. The tests have been carried out from 10 am to $3 \mathrm{pm}$. Following the requirement of the ASHRAE (2010) standard, each test was performed in several days, and the best experimental data were chosen. For steady-state efficiency tests, the mass flow rate must be held within $\pm 1 \%$, solar radiation must be steady within $\pm 50 \mathrm{~W} / \mathrm{m}^{2}$, the variation of environment temperature must not more than $\pm 1.5 \mathrm{~K}$, and the inlet temperature must be within $\pm 0.1 \mathrm{~K}$. Steady-state conditions must be maintained for data period length of 


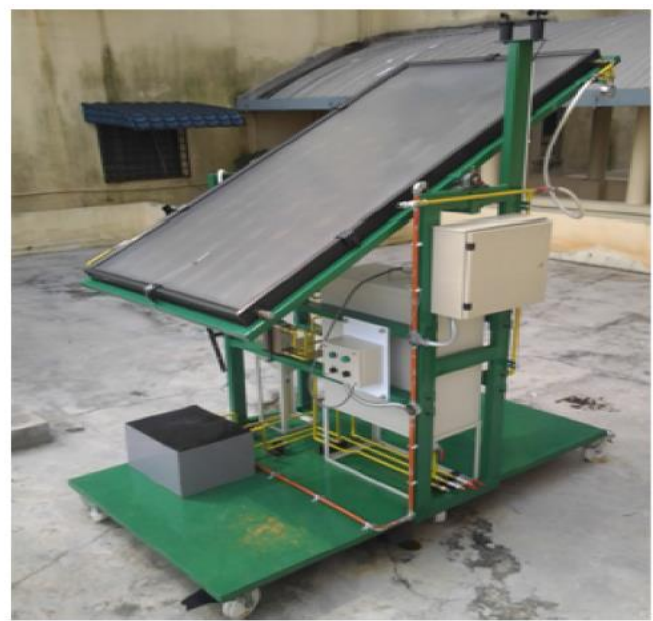

Fig. 4 Experimental setup

Table 2 Solar collector's specification

\begin{tabular}{ll}
\hline Specification & Dimension \\
\hline Dimension & $\begin{array}{l}2,000 \mathrm{~mm} \times 1,000 \mathrm{~mm} \times 80 \mathrm{~mm} \\
(L \times W \times T)\end{array}$ \\
Aperture area & $1.84 \mathrm{~m}^{2}$ \\
Weight & $36 \mathrm{~kg}$ \\
Cover material & $4 \mathrm{~mm}$ tempered texture glass \\
Heat transfer coefficient & $4.398 \mathrm{~W} /\left(\mathrm{m}^{2} \mathrm{~K}\right)$ \\
Absorber material & $0.4 \mathrm{~mm}$ aluminum \\
Header material & Copper TP2 \\
Header tube size & $22 \mathrm{~mm} \times 0.6 \mathrm{~mm}(\Phi x t), 2 \mathrm{pcs}$ \\
Riser tube material & Copper TP2 \\
Riser tube size & $10 \mathrm{~mm} \times 0.45 \mathrm{~mm}(\Phi x t), 8 \mathrm{pcs}$ \\
Absorption rate & 0.94 \\
Emittance & 0.12 \\
Frame & Aluminum alloy, anodized \\
\hline
\end{tabular}

$5 \mathrm{~min}$ and pre-data period of $15 \mathrm{~min}$. Thermocouples were used in this experiment to measure the plate temperature, the fluid temperatures at the inlet and outlet of the solar collector, and the environment temperature. A pressure transducer was used to measure the pressure difference from the inlet and outlet of the solar collector. All readings from the thermocouples and the pressure transducer were recorded in the data logger. Solar radiation was recorded using a TES $1333 \mathrm{R}$ solar meter. The wind speed was measured by an anemometer. The entire measuring devices had been carefully calibrated before, during, and after the experiment.

\section{Analyses}

Error analysis

In any experiment, the measured quantities subject to uncertainties or error. Errors can be caused by various factors. The errors can be classified as systematic and random error. Systematics errors are errors that shifted or displaced the measurement values systematically such as incorrect calibration of equipment or incorrect adjustment of that device. Usually, systematic errors can be avoided and eliminated. Random errors, on the other hand, are errors which fluctuate from one measurement to the next. Random errors are unavoidable and must be accounted to indicate the accuracy of the measured data (Kotulski and Szczepinski 2010)

For a collection of measured data, it is very important to calculate the average or mean value $\bar{x}$. The mean value can be calculated as follows:

$\bar{x}=\frac{\sum x_{i}}{n}$

where $n$ is the number of times and $x_{i}$ is the measured quantity.

$\bar{x}$ The measurement of dispersion in the data collection relative to its average value is an important parameter in error analysis. The variance $s^{2}$ is the usual measure for estimating distribution dispersion. Variance is the arithmetical mean value of all squares of deviations of particular values $x_{i}$ from the average values of the entire samples and can be defined by the following formula (Kotulski and Szczepinski 2010):

$s^{2}=\frac{\sum\left(x_{i}-\bar{x}\right)^{2}}{n-1}$.

The quantity $s$ is called the standard deviation which determines the width of the distribution and can be calculated by

$s=\sqrt{s^{2}}$.

The uncertainty given by the manufacturer for all the measuring devices is $\pm 2 \%$ for PROVA (AV M-07) anemometer, $\leq \pm 0.06{ }^{\circ} \mathrm{C}$ for thermocouples, and $\leq \pm 2 \%$ for flow meter. After the uncertainties of measured data have been accounted, the uncertainty for calculated results will also be quantified using Kline and McClintock method (1953). 

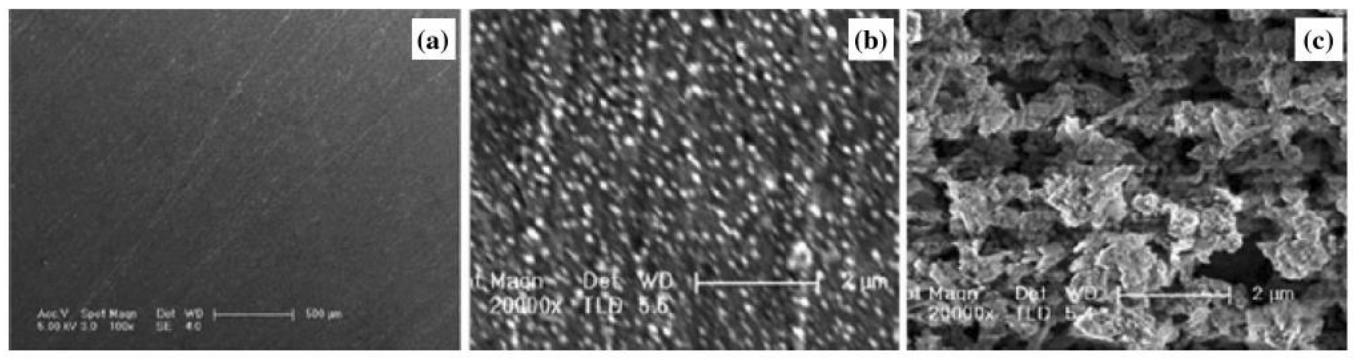

Fig. 5 SEM images of the heated surface of a before the experiment, b using the functionalized nanofluid, and $\mathbf{c}$ using the conventional nanofluid (Yang and Liu 2010)

Surface state of the heated surface

Nanoparticles had been reported to precipitate or fouled on the heated surface or on the flow conduit wall which will significantly change the surface characteristics that can potentially affect the thermal performance as well. Conventional $\mathrm{SiO}_{2}$ nanofluid (without surface coating) formed a fouling layer of nanoparticles on the heated surface after the boiling experiment, and the fouling layer cannot be flushed away by water. However, for $\mathrm{SiO}_{2}$ nanoparticles coated with silane, no fouling layer exists after the boiling process. The SEM images of heated surface are shown in Fig. 5. As seen in Fig. 5, only scattered functionalized nanoparticles are observed on the heated surface which can be easily flushed away by water. Similar result was also shown by Chen et al. (2013) indicating that no deposition layer exists for functionalized nanofluid. The test had been repeated using distilled water again after nanofluid experiment to check if the nanoparticle precipitation on the flow conduits will significantly change the surface characteristics that can potentially affect the thermal performance of the solar collector. From the test, the results shown that there is no significant impact of using functionalized nanofluid on surface characteristics of solar collector. The results obtained using distilled water after nanofluid experiment were similar with the one before nanofluid had been applied in the solar collector.

Efficiency analysis of nanofluid-based flat-plate solar collector

The collector thermal efficiency can be calculated from the ratio of the useful energy to the energy incident on the collector. Flat-plate collectors can collect both direct and diffuse solar radiation. To predict and model the collector performance, information on the solar energy absorbed by the collector absorber plate is needed. The solar energy incident radiation on a tilted surface consists of beam, diffuse, and ground-reflected radiation (Kalogirou 2009).
The beam and diffuse solar radiation will travel through the transparent cover. Increase in transmittance $(\tau)$ of the glazing of solar collector will result in more radiation received by the absorber plate. The energy will be absorbed in a fraction equal to the absorptivity $(\alpha)$ of the black absorber plate. Absorptivity would be one for the perfect blackbody absorber. The instantaneous energy gained by the receiver can be determined by Foster et al. (2009)

$\dot{Q}_{\mathrm{r}}=\dot{q}_{\mathrm{r}} A_{\mathrm{p}}=(\tau \alpha)_{\mathrm{eff}} I_{\mathrm{T}} A_{\mathrm{p}}$,

where $(\tau \alpha)_{\text {eff }}$ is the effective optical fraction of the energy absorbed, $\tau$ is the transmissibility of the transparent cover, $\alpha$ is the absorptivity of the absorber, $A_{\mathrm{p}}$ is the collector aperture area (the frontal opening area of the collector), and $I_{\mathrm{T}}$ is the solar radiation incident on the tilted collector. $I_{\mathrm{T}}$ is the sum of component of beam radiation $I_{\mathrm{b}}$, sky diffuse radiation $I_{\mathrm{d}}$, and ground-reflected solar radiation $I_{\mathrm{r}}$, and can be expressed as

$I_{\mathrm{T}}=I_{\mathrm{b}}+I_{\mathrm{d}}+I_{\mathrm{r}}$

The radiation will be absorbed and heat the absorber plate. Generally, solar collectors have great heat losses. The purpose of glazing is to prevent infrared thermal energy to escape. However, the temperature difference between the absorber plate and the ambient causes heat losses by convection to the surroundings. This heat loss can be calculated by Foster et al. (2009)

$\dot{Q}_{\text {conv }}=\dot{q}_{\text {conv }} A_{\mathrm{p}}=U A_{\mathrm{p}}\left(T_{\mathrm{p}}-T_{\mathrm{a}}\right)$,

where $U$ is the overall heat loss coefficient, $T_{\mathrm{P}}$ is absorber's plate temperature, and $T_{\mathrm{a}}$ is the ambient temperature.

The heat lost rate by radiation can be calculated by Foster et al. (2009)

$\dot{Q}_{\mathrm{rad}}=\dot{q}_{\mathrm{rad}} A_{\mathrm{p}}=\varepsilon_{\mathrm{eff}} \sigma A_{\mathrm{p}}\left(T_{P}^{4}-T_{a}^{4}\right)$,

where $\varepsilon_{\text {eff }}$ is the effective emissivity of the collector and $\sigma$ is Stefan-Boltzmann constant.

The heat losses from the bottom and from the edges of the collector are very small due to the insulation and can be 
neglected. Combining Eqs. (8) and (9) above, the useful energy collected can be represented as

$$
\begin{aligned}
\dot{Q}_{\mathrm{u}} & =\dot{q}_{\mathrm{u}} A_{\mathrm{p}} \\
& =(\tau \alpha)_{\mathrm{eff}} I_{\mathrm{T}} A_{\mathrm{p}}-U A_{\mathrm{p}}\left(T_{\mathrm{p}}-T_{\mathrm{a}}\right)-\varepsilon_{\mathrm{eff}} \sigma A_{\mathrm{p}}\left(T_{\mathrm{p}}^{4}-T_{\mathrm{a}}^{4}\right) .
\end{aligned}
$$

The heat-conducting fluid is the important of all for this analysis. The fluid will pass through pipes attached to the absorber plate. The fluid will absorb heat from the plate as it flows through the pipes and increased its temperature for useful application. The thermal efficiency of a solar collector can be calculated as

$\eta=\frac{\dot{Q}_{\mathrm{u}}}{I_{\mathrm{T}} A_{\mathrm{p}}}$.

To relate the collector's actual performance directly and in terms of the temperature of the useful heat energy from the circulating fluid, the efficiency and the useful heat gain can be calculated from

$\eta=F_{\mathrm{R}}\left[(\tau \alpha)_{\mathrm{eff}}-\frac{U A_{\mathrm{p}}}{I_{\mathrm{T}} A_{\mathrm{p}}}\left(T_{\mathrm{in}}-T_{\mathrm{a}}\right)\right]$,

$\dot{Q}_{\mathrm{u}}=\eta I_{\mathrm{T}} A_{\mathrm{p}}=I_{\mathrm{T}} A_{\mathrm{p}} F_{\mathrm{R}}\left[(\tau \alpha)_{\mathrm{eff}}-\frac{U A_{\mathrm{p}}}{I_{\mathrm{T}} A_{\mathrm{p}}}\left(T_{\mathrm{in}}-T_{\mathrm{a}}\right)\right]$,

where $F_{\mathrm{R}}$ is the effectiveness removal factor and $T_{\text {in }}$ is the fluid inlet temperature.

The important useful heat gain by the working fluid can be expressed as

$\dot{Q}_{\mathrm{u}}=\dot{m} C_{\mathrm{p}}\left(T_{\text {out }}-T_{\text {in }}\right)$,

where $T_{\text {out }}$ is the fluid outlet temperature, $C_{\mathrm{p}}$ is the heat capacity at constant pressure, and $\dot{m}$ is the mass flow rate of the working fluid.

The heat capacity of nanofluid can be calculated by Zhou and Ni (2008)

$C_{\mathrm{p}, \mathrm{nf}}=C_{\mathrm{p}, \mathrm{np}}\left(\varphi_{\mathrm{n}}\right)+C_{\mathrm{p}, \mathrm{bf}}\left(1-\varphi_{\mathrm{n}}\right)$,

where $C_{\mathrm{p}, \mathrm{nf}}$ is the heat capacity of nanofluid, $C_{\mathrm{p}, \mathrm{np}}$ is the heat capacity of nanoparticles, $C_{\mathrm{p}, \mathrm{bf}}$ is the heat capacity of base fluid, and $\varphi_{\mathrm{n}}$ is the volume fraction of nanoparticles in nanofluid.

When there is no fluid flow, the temperature of the absorber can be defined as stagnation temperature (Singal 2008):

$T_{\text {stag }}=T_{\mathrm{a}}+\frac{I_{\mathrm{T}} F_{\mathrm{R}}(\tau \alpha)_{\mathrm{eff}}}{\left(F_{\mathrm{R}} U\right) R}$.

From all these expressions, the useful heat gain and the efficiency of collectors can be calculated and compared between the conventional working fluid and $\mathrm{SiO}_{2}$ nanofluids.
Exergy analysis of nanofluid-based flat-plate solar collector

Exergy is the maximum output that can be achieved relative to the environment temperature. The general equation of the exergy balance is (Farahat et al. 2009; Suzuki 1988)

$\dot{E}_{\text {in }}+\dot{E}_{\mathrm{s}}+\dot{E}_{\text {out }}+\dot{E}_{\mathrm{l}}+\dot{E}_{\mathrm{d}}=0$,

where $\dot{E}_{\text {in }}$ is the inlet exergy rate, $\dot{E}_{\mathrm{s}}$ is the stored exergy rate, $\dot{E}_{\text {out }}$ is the outlet exergy rate, $\dot{E}_{1}$ is the leakage exergy rate, and $\dot{E}_{\mathrm{d}}$ is the destroyed exergy rate.

The inlet exergy rate measures the fluid flow and the absorbed solar radiation rate. The inlet exergy rate with fluid flow can be calculated by Farahat et al. (2009)

$\dot{E}_{\text {in }, \mathrm{f}}=\dot{m} C_{\mathrm{p}}\left(T_{\text {in }}-T_{\mathrm{a}}-T_{\mathrm{a}} \ln \left(\frac{T_{\mathrm{in}}}{T_{\mathrm{a}}}\right)\right)+\frac{\dot{m} \Delta P_{\text {in }}}{\rho}$,

where $\Delta P_{\text {in }}$ is the pressure difference of the fluid with the surroundings at entrance and $\rho$ is the fluid density.

The absorbed solar radiation exergy rate can be calculated as

$\dot{E}_{\mathrm{in}, \mathrm{Q}}=\eta I_{\mathrm{T}} A_{\mathrm{p}}\left(1-\frac{T_{\mathrm{a}}}{T_{\mathrm{s}}}\right)$,

where $T_{\mathrm{s}}$ is the apparent sun temperature and equals to $75 \%$ of blackbody temperature of the sun (Bejan et al. 1981).

Total inlet exergy rate of the solar collector can be calculated from

$\dot{E}_{\text {in }}=\dot{E}_{\text {in }, \mathrm{f}}+\dot{E}_{\text {in }, \mathrm{Q}}$.

At steady-state conditions, where the fluid is flowing, the stored exergy rate is zero:

$\dot{E}_{\mathrm{s}}=0$.

When only the exergy rate of the outlet fluid flow is considered, the outlet exergy rate can be defined as (Kotas 1995)

$\dot{E}_{\text {out }, \mathrm{f}}=-\dot{m} C_{\mathrm{p}}\left(T_{\text {out }}-T_{\mathrm{a}}-T_{\mathrm{a}} \ln \left(\frac{T_{\text {out }}}{T_{\mathrm{a}}}\right)\right)+\frac{\dot{m} \Delta P_{\text {out }}}{\rho}$.

The heat leakage from the absorber plate to the environment can be defined as the leakage exergy rate and calculated as (Gupta and Saha 1990)

$\dot{E}_{1}=-U A_{\mathrm{p}}\left(T_{\mathrm{p}}-T_{\mathrm{a}}\right)\left(1-\frac{T_{\mathrm{a}}}{T_{\mathrm{p}}}\right)$.

The destroyed exergy rate caused by the temperature difference between the absorber plate surface and the sun can be expressed as (Gupta and Saha 1990) 
$\dot{E}_{\mathrm{d}, \Delta \mathrm{T}_{\mathrm{s}}}=-\eta I_{\mathrm{T}} A_{\mathrm{p}} T_{\mathrm{a}}\left(\frac{1}{T_{\mathrm{p}}}-\frac{1}{T_{\mathrm{s}}}\right)$.

The destroyed exergy rate by pressure drop is expressed by (Suzuki 1988)

$\dot{E}_{\mathrm{d}, \Delta \mathrm{P}}=-\frac{\dot{m} \Delta P}{\rho} \frac{T_{\mathrm{a}} \ln \left(\frac{T_{\text {out }}}{T_{\mathrm{a}}}\right)}{\left(T_{\text {out }}-T_{\text {in }}\right)}$.

The destroyed exergy rate caused by the temperature difference between the absorber plate surface and the agent fluid can be calculated using the following relation (Suzuki 1988):

$\dot{E}_{\mathrm{d}, \Delta T_{\mathrm{f}}}=-\dot{m} C_{\mathrm{p}} T_{\mathrm{a}}\left(\ln \left(\frac{T_{\text {out }}}{T_{\mathrm{in}}}\right)-\frac{\left(T_{\text {out }}-T_{\mathrm{in}}\right)}{T_{\mathrm{p}}}\right)$.

The total destroyed exergy rate can be calculated from $\dot{E}_{\mathrm{d}}=\dot{E}_{\mathrm{d}, \Delta \mathrm{T}_{\mathrm{s}}}+\dot{E}_{\mathrm{d}, \Delta \mathrm{P}}+\dot{E}_{\mathrm{d}, \Delta \mathrm{T}_{\mathrm{f}}}$.

The exergy destruction rate can also be expressed as

$\dot{E}_{\mathrm{d}}=T_{\mathrm{a}} \dot{S}_{\mathrm{gen}}$

where $\dot{S}_{\text {gen }}$ is the overall rate of entropy generation and can be calculated from (Bejan 1996)

$\dot{S}_{\mathrm{gen}}=\dot{m} C_{\mathrm{p}} \ln \frac{T_{\mathrm{out}}}{T_{\mathrm{in}}}-\frac{\dot{Q}_{\mathrm{S}}}{T_{\mathrm{S}}}+\frac{\dot{Q}_{\mathrm{O}}}{T_{\mathrm{a}}}$,

where $\dot{Q}_{\mathrm{S}}$ is the solar energy rate absorbed (W) by the collector surface as expressed by (Esen 2008)

$\dot{Q}_{\mathrm{S}}=I_{\mathrm{T}}(\tau \alpha) A_{\mathrm{p}}$,

and $\dot{Q}_{\mathrm{O}}$ is the heat loss rate to the environment (W):

$\dot{Q}_{\mathrm{O}}=\dot{Q}_{\mathrm{S}}-\dot{m} C_{\mathrm{p}}\left(T_{\text {out }}-T_{\text {in }}\right)$.

Ultimately, combining all the expression above, the exergy efficiency equation of the solar collector can be given as follows (Farahat et al. 2009):

$\eta_{\mathrm{ex}}=\frac{\dot{m}\left[C_{\mathrm{p}}\left(T_{\text {out }}-T_{\mathrm{in}}-T_{\mathrm{a}} \ln \left(\frac{T_{\text {out }}}{T_{\text {in }}}\right)\right)-\frac{\Delta P}{\rho}\right]}{I_{\mathrm{T}} A_{\mathrm{p}}\left(1-\frac{T_{\mathrm{a}}}{T_{\mathrm{s}}}\right)}$.

Pumping power

In this system, an electrical powered pump is required to pump the working fluid throughout the collector. To analyze the pumping energy needed by the system, the expressions from White (2003) and Garg and Agarwal (1995) were used. The pressure drop in the system can be calculated from
$\Delta P=f \frac{\rho V^{2}}{2} \frac{\Delta L}{D}+K \frac{\rho V^{2}}{2}$,

where $f$ is the friction factor, $K$ is the loss coefficient, and $D$ is the diameter of the pipe. $V$ is the velocity $(\mathrm{m} / \mathrm{s})$ of the working fluid and can be calculated from

$V=\frac{\dot{m}}{\rho_{\mathrm{nf}} \pi D^{2} / 4}$.

The density of nanofluid can be calculated from

$\rho_{\mathrm{nf}}=\rho_{\mathrm{np}}\left(\varphi_{\mathrm{n}}\right)+\rho_{\mathrm{bf}}\left(1-\varphi_{\mathrm{n}}\right)$.

The friction factors for laminar flow $\left(R e \leq 2 \times 10^{5}\right)$ and turbulent flow $\left(\operatorname{Re} \leq 2 \times 10^{5}\right)$ can be calculated from (35) and (36), respectively (Bergman et al. 2011; Kahani et al. 2013):

$f=\frac{64}{R e}$,

$f=\frac{0.079}{(\operatorname{Re})^{1 / 4}}$.

The Reynolds number can be expressed as

$R e=\frac{\rho V D}{\mu}$,

where $\mu$ is the viscosity of the working fluid $(0.0008$ $\mathrm{kg} / \mathrm{m} \mathrm{s}$ for water) and the viscosity of nanofluid was measured using LVD-III ultra-programmable rheometer (Brookfield, USA).

Finally, the pumping power can be obtained using

$\dot{W}_{\text {pumping }}=\left(\frac{\dot{m}}{\rho_{\mathrm{nf}}}\right) \times \Delta P$.

Heat transfer

The convective heat transfer coefficient in this study can be calculated from

$h=\frac{Q_{\mathrm{u}}}{A_{\mathrm{p}}\left(T_{\mathrm{p}}-T_{\mathrm{b}}\right)}$,

where $T_{\mathrm{b}}$ is the bulk temperature and can be calculated from

$T_{\mathrm{b}}=\frac{T_{\text {in }}+T_{\text {out }}}{2}$.

The heat transfer coefficient can also be obtained from Li et al. (2003)

$h=\frac{q}{T_{\mathrm{p}}-T_{\mathrm{nf}}}$,

where $q$ is the heat flux $\left(\mathrm{W} / \mathrm{m}^{2}\right)$.

From there, the Nusselt number can be calculated as 
$N u_{\mathrm{nf}}=\frac{h_{\mathrm{nf}} D}{k_{\mathrm{nf}}}$.

For the laminar flow of circular pipe, the Nusselt number can be calculated from the Reynolds and Prandtl numbers expressed by Owhaib and Palm (2004)

$N u=0.000972 \operatorname{Re}^{1.17} \operatorname{Pr}^{1 / 3}$ for $R e<2,000$.

Prandtl number can be calculated from

$\operatorname{Pr}=\frac{C_{\mathrm{p}, \mathrm{nf}} \mu_{\mathrm{nf}}}{k_{\mathrm{nf}}}$.

The thermal conductivity can be expressed by

$\frac{k_{\mathrm{nf}}}{k_{\mathrm{f}}}=\frac{k_{\mathrm{p}}+(\mathrm{SH}-1) k_{\mathrm{f}}-(\mathrm{SH}-1) \varphi\left(k_{\mathrm{f}}-k_{\mathrm{p}}\right)}{k_{\mathrm{p}}+(\mathrm{SH}-1) k_{\mathrm{f}}+\varphi\left(k_{\mathrm{f}}-k_{\mathrm{p}}\right)}$,

where $\mathrm{SH}$ is the shape factor and assuming the spherical shape of nanoparticle, the factor can be taken as 3 ( $\mathrm{Li}$ et al. 2013).

Embodied energy analysis

After that, the embodied energy of a solar collector can be estimated. Only energy used to manufacture the solar collector is considered where else the distribution, maintenance, and disposal phases of the collectors are neglected. Due to more than $70 \%$ of the embodied energy of the system come from the manufacturing of the collector (Ardante et al. 2005), the analysis was done with the reduction of the collector area as the functional unit that influences the overall weight and embodied energy of the collector. Using the thermal efficiency data of the solar collector, the potential of reduction of the size of collector's area can be estimated by

$A_{\mathrm{p}}=\frac{\dot{m} C_{\mathrm{p}}\left(T_{\text {out }}-T_{\mathrm{in}}\right)}{I_{\mathrm{T}} \eta}$.

Two major materials are used in the solar collector namely glass and copper with the weight ratio of $27 \mathrm{~kg}$ glass and $9 \mathrm{~kg}$ copper for a $36 \mathrm{~kg}$ collector. The embodied energy indices are 15.9 and $70.6 \mathrm{MJ} / \mathrm{kg}$ for the glass and the copper, respectively (Otanicar et al. 2010). Using the result of size reduction, weight and embodied energy for the solar collector can be calculated accordingly.

Economic analysis

The results of the thermal performance of nanofluid solar collector and size reduction can also be used to estimate the cost saving. Using nanofluid as working fluid in the solar collector, large portion of the copper and the glass used in the system can be eliminated based on the scaling of the overall percentage weight of the collector. The capital cost
Table 3 Electricity generation by fuel type and primary emissions mix for Malaysia (Sustainable Energy Development 2010)

\begin{tabular}{lclll}
\hline Fuel & $\begin{array}{l}\text { \% of } \\
\text { Electricity } \\
\text { generated }\end{array}$ & $\begin{array}{l}\text { Carbon } \\
\text { dioxide, } \mathrm{CO}_{2} \\
(\mathrm{~kg} / \mathrm{MJ})\end{array}$ & $\begin{array}{l}\text { Sulfur } \\
\text { oxides, } \mathrm{SO}_{x} \\
(\mathrm{~kg} / \mathrm{MJ})\end{array}$ & $\begin{array}{l}\text { Nitrogen } \\
\text { oxides, } \mathrm{NO}_{x} \\
(\mathrm{~kg} / \mathrm{MJ})\end{array}$ \\
\hline Coal & 36.5 & 0.274 & 0.00031 & 0.0005 \\
Oil & 0.2 & 0.220 & 0 & 0 \\
Natural gas & 55.9 & 0.113 & 0 & 0.00003 \\
Hydro & 5.6 & 0 & 0 & 0 \\
Others & 1.8 & 0 & 0 & 0 \\
\hline
\end{tabular}

of the collector will then be offset by the cost of the nanoparticles. The energy usage per day in conjunction with the local electricity rates based on $0.07 \mathrm{USD} / \mathrm{kWh}$ for the first $200 \mathrm{kWh}$ and $0.10 \mathrm{USD}$ for the subsequent hour are used to determine the amount saved using a solar thermal system. Using a solar hot water system, $11.03 \%$ of electricity used for water heating in Malaysia can be saved (Lalchand 2012).

Environmental analysis

Burning of fossil fuels to generate the energy to heat water will result in harmful gas emissions. Switching to solar hot water system can reduce that problem. The distribution of electricity from various fuel types and the key pollutants generated in Malaysia is shown in Table 3.

With the data of the embodied energy index of the solar collector achieved from "Embodied energy analysis" section, the emissions from the manufacturing of the collectors can be determined. The offset damage costs can be calculated for the three main pollutants of $\mathrm{CO}_{2}, \mathrm{NO}_{x}$, and $\mathrm{SO}_{x}$ based on the damage cost factors (Spardo and Rabl 1999). These offset damage costs are not costs directly applicable to the collector owner.

\section{Results and discussion}

Error analysis

The distributions of the measured values of solar radiation, wind velocity, and temperatures are specified in Table 4. Standard deviation determines the width of the distribution. Errors are quoted in terms of the standard deviation. For measured solar radiation, the standard deviation was around $27.39 \mathrm{~W} / \mathrm{m}^{2}$ for the average value of $756.76 \mathrm{~W} / \mathrm{m}^{2}$. The standard deviations for measured plate temperature, inlet temperature, outlet temperature, and ambient temperature are $5.67,0.34,6.86$, and $1.21^{\circ} \mathrm{C}$, respectively. The maximum uncertainty obtained by combining both

\section{Link to full text journal articles :}

\section{http://link.springer.com/article/10.1007/s10098-014-0870-0}

